Jurnal Laut Khatulistiwa, Vol. 4 No. 2 (Juli, 2021), Hal. 64-68.

ISSN : 2614-6142 (Printed), 2614-8005 (Online)

http://jurnal.untan.ac.id/index.php/lk

JURNAL LAUT

KHATULISTIWA

\title{
Pengukuran Kadar Astaxanthin dan Aktivitas Antioksidan dalam Fraksi Lipid Cincalok
}

\section{Measurement of Astaxanthin Levels and Antioxidant Activity in the Cincalok Lipid Faction}

\author{
Alya Selviana ${ }^{*}$, Warsidah ${ }^{2}$, Dwi Imam Prayitno² \\ ${ }_{1}^{1}$ Program Studi Ilmu Kelautan, FMIPA Universitas Tanjungpura, Pontianak, Indonesia \\ ${ }_{1}^{1}$ Laboratorium Ilmu Kelautan, FMIPA Universitas Tanjungpura, Pontianak, Indonesia \\ *E-mail : alyaselviana4@gmail.com
}

Received : 10 April 2021; Accepted: 16 Juni 2021

Published: 31 Juli (C) Author(s) 2021. This article is open access

\begin{abstract}
Cincalok is one of the products of the management of typical shrimp of West Kalimantan made by the fermentation process. This fermented food contains antioxidant compounds, one of which is astaxanthin. Astaxanthin is widely used in making cosmetics and health products. The purpose of this study was to determine the antioxidant activity and levels of astaxanthin found in cincalok lipids. This research was carried out extraction using socletation method with $n$-hexane solvent, the average yield obtained was $6.75 \%$. Then determine the antioxidant activity of cincalok using the DPPH method and measurement of astaxanthin levels using a UV-Vis spectrophotometer with a wavelength of $477 \mathrm{~nm}$. The results of the study of the antioxidant activity of cincalok lipids had weak antioxidant activity with an IC 50 value of $207.18 \mathrm{ppm}$. Astaxanthin cincalok lipid fraction contains an average astaxanthin level of 0,0179 $\mathrm{mg}$ in $10 \mathrm{mg}$.
\end{abstract}

Keywords : Cincalok, Astaxanthin, Antioxidant

\begin{abstract}
Abstrak
Cincalok merupakan salah satu produk hasil pengelolaan udang khas Kalimantan Barat yang dibuat dengan proses fermentasi. Makanan fermentasi ini memiliki kandungan senyawa antioksidan salah satunya astaxanthin. Astaxanthin banyak dimanfaatkan dalam pembuatan produk kosmetik dan kesehatan. Tujuan dari penelitian ini adalah untuk mengetahui aktivitas antioksidan dan kadar astaxanthin yang terdapat pada lipid cincalok. Penelitian ini dilakukan ekstraksi menggunakan metode sokletasi dengan pelarut nheksan rata-rata rendemen yang didapat adalah 6,75 \%. Kemudian dilakukan penentuan aktivitas antioksidan cincalok menggunakan metode DPPH dan pengukuran kadar astaxanthin menggunakan spektrofotometer UV-Vis dengan panjang gelombang $477 \mathrm{~nm}$. Hasil penelitian dari aktivitas antioksidan lipid cincalok memiliki aktivitas antioksidan lemah dengan nilai IC 50 $_{0}$ 207,18 ppm. Astaxanthin fraksi lipid cincalok dalam $10 \mathrm{mg}$ mengandung kadar astaxanthin rata-rata sebesar 0,0179 mg.
\end{abstract}

Kata kunci : Cincalok, Astaxanthin, Antioksidan

\section{Pendahuluan}

Cincalok merupakan salah satu produk hasil pengelolaan udang khas Kalimantan Barat yang dibuat dengan proses fermentasi berbahan dasar udang rebon (Acetes s.p), gula, dan garam. Lipid yang terdapat pada udang rebon memiliki kandungan gizi omega 3 pospolipid yang tinggi, 15,69\% asam dokosaheksanoat (DHA) dan 13,45\% asam eikosapentanoat (EPA) dan antioksidan alami yang bermanfaat bagi kesehatan manusia (Balange et al., 2017; Faithong N, et al., 2010).

Antioksidan alami yang terdapat pada produk fermentasi ini yaitu astaxanthin. Astaxanthin terurai dari proses hasil 
Jurnal Laut Khatulistiwa, Vol. 4. No. 2 (Juli, 2021), Hal. 64-68.

fermentasi laktat sehingga menyebabkan perubahan warna merah muda pada produk fermentasi udang rebon (Rahmayati et al., 2014). Kandungan astaxanthin dalam udang utuh beku setiap 100 gram berat basah yaitu $3,12 \mathrm{mg}$ dan dalam bentuk pasta (terasi) nilai astaxanthin berturut-turut $6,0 \mathrm{mg} / 100 \mathrm{~g}, 4,5$ $\mathrm{mg} / 100 \mathrm{~g}$, dan 2,4 mg/100g (Rahmayati et al., 2014). Pada penelitian Sachindra et al. (2006) ekstraksi karotenoid udang menggunakan pelarut aseton dengan kadar karotenoid yang didapatkan sebesar 10,4-17,4 $\mu \mathrm{g} / \mathrm{g}$ dalam daging udang, 35,8-153,1 $\mu \mathrm{g} / \mathrm{g}$ dalam kepala udang dan 59,8-104,7 $\mu \mathrm{g} / \mathrm{g}$ dalam kulit udang. Pada ekstraksi menggunakan minyak nabati diperoleh astaxanthin sebesar 29,814 $\mu \mathrm{g} / \mathrm{g}$ (Silva, Rodrigues, 2018).

Keunggulan lipid memiliki banyak manfaat khususnya dalam pembuatan produk kesehatan dan kosmetik. Saat ini produk kesehatan dan kosmetik yang kaya antioksidan alami sangat diminati oleh kalangan masyarakat seperti lipid ikan yang banyak ditemukan dan digunakan sebagai bahan dasar produk kesehatan dan kosmetik. Pada penelitian ini diharapkan lipid yang terdapat pada udang rebon fermentasi memberikan keunikan tersendiri dari senyawa astaxanthin yang dimiliki sehingga dapat diaplikasikan menjadi bahan antioksidan alami yang memberi manfaat lebih dari cincalok. Oleh karena itu, peneliti ingin mengetahui seberapa besar kadar astaxanthin dan aktivitas antioksidan dari fraksi lipid cincalok. Pemanfaatan kandungan senyawa astaxanthin yang terdapat pada udang terfermentasi (cincalok) diharapkan memberikan peluang dalam meningkatkan nilai guna cincalok khas Kalimantan Barat menjadi produk lokal yang memiliki nilai ekonomi tinggi bagi masyarakat.

\section{Metodologi Penelitian}

\subsection{Alat dan bahan}

Alat yang digunakan adalah alumunium foil, aquades, botol vial, corong pisah, gelas kimia, gelas ukur, kertas saring, mikropipet, mortar, neraca analitik, pipet tetes, pipet volume, spatula, saringan, spektofotometri UVVIS, stopwatch, vaccum drying, dan wrapping. Bahan yang digunakan adalah aceton, akuades, cincalok, metanol, n-heksan, bubuk DPPH 2,2diphenyl-1-picrihydrazyl).

\subsection{Preparasi Sampel}

Preparasi sampel dilakukan proses pengeringan dan penghancuran sampel. Sampel disaring terlebih dahulu kemudian ditimbang dan dikeringkan menggunakan vacuum drying. Sampel yang sudah kering kemudian dihaluskan menggunakan grinder.

\subsection{Ekstraksi}

Ekstraksi sampel menggunakan metode sokletasi. Ekstraksi dilakukan selama 2 jam dengan pelarut n-heksan sebanyak $250 \mathrm{ml}$ dengan suhu $60-70^{\circ} \mathrm{C}$. Hasil ekstraksi kemudian didestilasi dan dikeringkan dengan hairdryer untuk menghilangkan pelarut n-

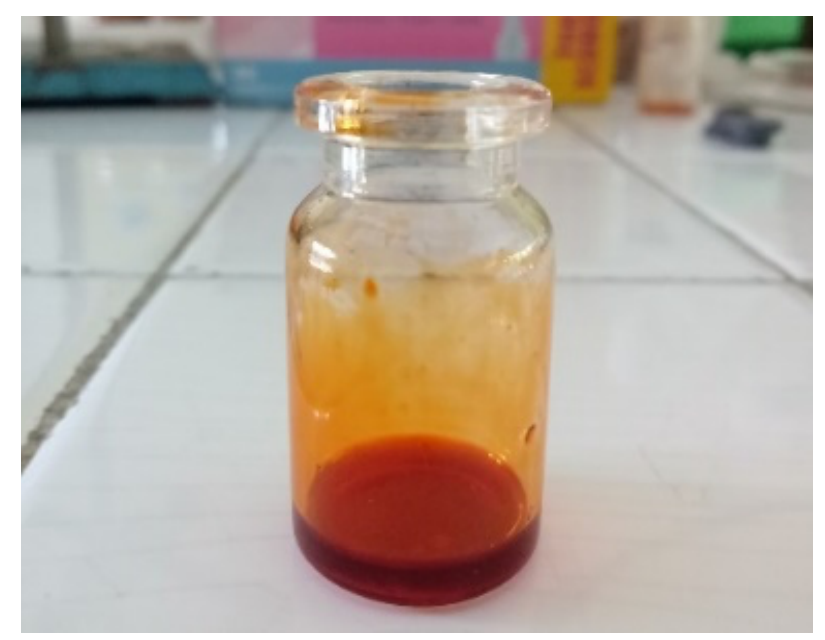

Gambar 1. Hasil Ekstraksi Lipid Cincalok 
Jurnal Laut Khatulistiwa, Vol. 4. No. 2 (Juli, 2021), Hal. 64-68.

heksan. Proses ekstraksi dilakukan sebanyak 3 kali.

\subsection{Uji Aktivitas Antioksidan}

Ekstrak Lipid cincalok dibuat larutan dengan konsentrasi 50, 100, 150, 200, dan 250 ppm dan asam askorbat sebagai pembanding dibuat larutan dengan konsentrasi 2, 4, 6, dan 8 ppm. Sebanyak $1 \mathrm{ml}$ dari masing-masing konsentrasi larutan sampel fraksi lipid dimasukan dalam tabung reaksi, ditambah 1 $\mathrm{ml}$ DPPH $100 \mu \mathrm{g} / \mathrm{ml}$, diencerkan dengan $2 \mathrm{ml}$ metanol p.a dan dihomogenkan. Penghambatan senyawa radikal DPPH ditentukan menggunakan spektrofotometer UV-VIS pada panjang gelombang $516 \mathrm{~nm}$ kemudian dihitung nilai $\mathrm{IC}_{50}$.

\subsection{Pengukuran Kadar Astaxanthin}

Sampel yang telah diekstraksi $10 \mathrm{mg}$ ditambahkan pelarut aseton p.a. dimasukkan ke dalam labu ukur 10 sampai tanda batas dan dikocok hingga homogen lalu disaring dengan kertas saring. Kemudian diukur serapannya menggunakan spektrofotometer UV-Vis pada panjang gelombang maksimum $477 \mathrm{~nm}$. Absorbansi yang diperoleh kemudian dimasukkan kedalam persamaan

$$
y=b x+a
$$

\section{Hasil dan Pembahasan}

\subsection{Preparasi Sampel}

Preparasi sampel cincalok dilakukan melalui tahapan pengeringan dan penghalusan. Pada tahap pengeringan ini sampel cincalok disaring terlebih dahulu untuk memisahkan air dengan residunya. Sampel kemudian dikeringkan menggunakan mesin vaccum drying dengan suhu $40-50^{\circ} \mathrm{C}$ selama \pm 3-6 jam. Sampel cincalok yang sudah kering kemudian ditimbang dan berat kering yang didapat sebesar 321,3 gr dari berat basah 1.225,6 gr. Tujuan dari tahap pengeringan untuk mengurangi kadar air pada cincalok dan menjamin kelembaban produk dan menurunkan kadar air yang terkandung pada udang cincalok agar tidak dapat memudahkan produk ditumbuhi jamur dan kapang yang dapat mengakibatkan produk mengalami pembusukan. Sampel yang sudah kering kemudian dihaluskan menggunakan grinder. Proses penghalusan simplisia menjadi bentuk pasta akan memudahkan proses penyarian senyawa aktif dari bahan organik. Luas permukaan yang kecil dari bahan akan mempercepat laju ekstraksi, sehingga senyawa aktif yang berada di dalamnya akan lebih cepat larut dan tersari lebih banyak (Wahyuni, 2020).

\subsection{Ekstraksi}

Tujuan dilakukan proses ekstraksi untuk memisahkan atau menarik komponen kimia yang terdapat pada sampel udang rebon fermentasi (cincalok) menggunakan pelarut. Metode ekstraksi yang digunakan pada penelitian ini yaitu sokletasi dengan pelarut nheksan. Hasil rendemen rata-rata rendemen yang didapat dari ekstraksi ini adalah 6,95 \%. Tingginya rendemen dihasilkan dapat menghasilkan nilai ekstrak yang semakin banyak. Hasil rendemen dapat mempengaruhi oleh proses fermentasi yang terjadi pada cincalok dimana umumnya fermentasi merupakan salah satu metode yang dapat menghancurkan dinding sel bahan baku fermentasi (Djohny, 2018).

\subsection{Pengukuran Kadar Astaxanthin}

Pengukuran kadar astaxanthin menggunakan spektrofotometri UV-Vis dengan serapan panjang gelombang kadar staxanthin dari rentang 400-750 $\mathrm{nm}$. Hal ini disesuaikan dengan rentang puncak maksimum yang umumnya dimiliki oleh astaxanthin pada beberapa penelitian sebelumnya. Pengukuran kurva standar astaxanthin standar pada Tabel 1 dilakukan pengulangan menggunakan panjang gelombang $477 \mathrm{~nm}$. Hasil pengukuran menunjukkan nilai $r$ yaitu 0,998 sehingga diperoleh persamaan kurva baku $y=0,3164 x+$ 0,0313. Peningkatan kadar astaxanthin pada lipid cincalok pada penelitian ini diduga dipengaruhi kondisi sampel yang sudah dikeringkan dibanding penelitian sebelumnya dengan kondisi sampel basah. Pengeringan dengan vaccum drying dapat mengurangi kadar air sehingga astaxanthin dalam lipid cincalok dapat diperoleh cukup maksimal. Sampel kering cincalok memudahkan senyawa 
Jurnal Laut Khatulistiwa, Vol. 4. No. 2 (Juli, 2021), Hal. 64-68.

Tabel 1. Pengukuran Kadar Astaxanthin dalam Lipid Cincalok

\begin{tabular}{ccc}
\hline Pegulangan & Absorbansi & $\begin{array}{c}\text { Kadar Astaxanthin } \\
\text { Lipid Cincalok }\end{array}$ \\
\hline 1 & 0.625 & 0.0188 \\
2 & 0.601 & 0,0180 \\
3 & 0.563 & 0,0168
\end{tabular}

Tabel 2. Uji Aktivitas Antioksidan Sampel Lipid Cincalok dan asam askorbat

\begin{tabular}{lllllll}
\hline \multirow{2}{*}{ Sampel } & \multicolumn{5}{c}{ Inhibisi } & \multirow{2}{*}{ IC $_{50}$} \\
\cline { 2 - 6 } & $50 \mathrm{ppm}$ & $100 \mathrm{ppm}$ & $\begin{array}{l}150 \\
\mathrm{ppm}\end{array}$ & $\begin{array}{l}200 \\
\mathrm{ppm}\end{array}$ & $\begin{array}{l}250 \\
\mathrm{ppm}\end{array}$ & \\
\hline $\begin{array}{l}\text { Lipid } \\
\text { Cincalok }\end{array}$ & $19.38 \%$ & $36.43 \%$ & $42.84 \%$ & $50.08 \%$ & $53.92 \%$ & 207.18 \\
\hline $\begin{array}{l}\text { Asam } \\
\text { Askorbat }\end{array}$ & $2 \mathrm{ppm}$ & $4 \mathrm{ppm}$ & $6 \mathrm{ppm}$ & $8 \mathrm{ppm}$ & $10 \mathrm{ppm}$ & 5.53 \\
\cline { 2 - 6 } & $29.41 \%$ & $40.87 \%$ & $51.21 \%$ & $67.42 \%$ & $74.74 \%$ & \\
\hline
\end{tabular}

astaxanthin dalam lipid cincalok terlarut dalam pelarut $n$-heksan pada saat ekstraksi.

\subsection{Aktivitas Antioksidan}

Pengukuran aktivitas antioksidan sampel lipid cincalok dan pembandingnya dilakukan pengujian kuantitatif. Berdasarkan hasil uji aktivitas antioksidan semakin tinggi konsentrasi larutan sampel maka \% inhibisinya semakin tinggi dalam menangkap radikal bebas. Peningkatan persen inhibisi dipengaruhi oleh menurunnya nilai absorbansi yang dihasilkan oleh sampel. Penurunan nilai absorbansi disebabkan oleh tingginya konsentrasi sampel. Senyawa dikatakan sebagai antioksidan sangat kuat apabila nilai $\mathrm{IC}_{50}$ kurang dari $50 \mu \mathrm{g} / \mathrm{ml}$, kuat apabila nilai $\mathrm{IC}_{50}$ antara $50-100 \mu \mathrm{g} / \mathrm{ml}$, sedang apabila nilai $\mathrm{IC}_{50}$ berkisar antara $100-150 \mu \mathrm{g} / \mathrm{ml}$, dan lemah apabila nilai $\mathrm{IC}_{50}$ berkisar antara 150-200 $\mu \mathrm{g} / \mathrm{ml}$. Perhitungan nilai $\mathrm{IC}_{50}$ digunakan dalam menentukan aktivitas penangkapan radikal bebas. Hasil uji antioksidan dapat dilihat pada Tabel 2 nilai $\mathrm{IC}_{50}$ sampel lipid cincalok lebih tinggi dibanding asam askorbat. Nilai $\mathrm{IC}_{50}$ yang diperoleh dapat dilihat pada Tabel 2. Sampel lipid cincalok diperoleh 207,18 ppm sedangkan asam askorbat nilai $\mathrm{IC}_{50}$ yang didapat lebih rendah yaitu 5,53 ppm.

Aktivitas antioksidan yang dimiliki sampel lipid cincalok tergolong lemah dibandingkan asam askorbat. Pada penelitian ini kadar astaxanthin yang diperoleh cukup tinggi namun, setelah dilakukan uji aktivitas antioksidan, lipid cincalok tergolong sebagai antioksidan yang lemah. Hal ini dikarenakan struktur rantai yang dimiliki astaxanthin tidak jenuh sehingga senyawa ini menjadi sangat sensitif terhadap panas, cahaya dan kondisi oksidatif serta faktor lingkungan yang dapat mempengaruhi stabilitas astaxanthin (Franco, et al., 2010). Beberapa faktor tersebut menjadi kelemahan senyawa astaxanthin sebagai senyawa antioksidan (Ngginak, 2013; Roopyai et al., 2012). Proses pengeringan dan pemanasan yang dilakukan saat ekstraksi mempengaruhi aktivitas antioksidan pada sampel lipid cincalok.

\section{Kesimpulan}

Kesimpulan dari penelitian ini adalah:

1. Aktivitas antioksidan fraksi lipid udang fermentasi yaitu 207,18 ppm. Aktivitas antioksidan yang dimiliki termasuk dalam kategori lemah.

2. Astaxanthin fraksi lipid cincalok mengandung kadar astaxanthin rata-rata sebesar 0,0179 mg dalam $10 \mathrm{mg}$ lipid cincalok

\section{Daftar Pustaka}

Djonny, M. 2018. Pengaruh Waktu Fermentasi Daun Nilam Menggunakan Rhizopus sp. Terhadap Rendemen Minyak Nilam. 
Jurnal Laut Khatulistiwa, Vol. 4. No. 2 (Juli, 2021), Hal. 64-68.

Sinergitas Multidisiplin Ilmu Pengetahuan dan Teknologi, Jurusan Teknik Kimia UKIPaulus Makassar.

Faithong, N, S. Benjakul, S. Phatcharat, W. Binsan. 2010. Chemical Composition and Antioxidative Activity of Thai Traditional Fermented Shrimp and Krill Products. J. Food Chemistry. 119: 133-140.

Faradilla, Aulia. 2020, Penetapan Kadar Astaxanthin dalam Udang Rebon dan cincalok, Jurusan Farmasi, Fakultas Kedokteran, Universitas Tanjungpura, Pontianak (Skripsi).

Franco, Z.M.E., P.R. Jimenez, C.A. Tomasini, dan L.I. Guerrero. 2010. Astaxanthin Extraction from Shrimp Wastes and Its Stability in 2 Model Systems. J. of Food Sci., 75(5): 394 399.

Goh, S. Wahyuni. 2020. Pengujian Indeks Busa, Indeks Ikan dan Indeks Hemolitik Cincalok yang diekstraksi Menggunakan VCO (Virgin Coconut Oil), J. Farmasi Untan., 4(1):1-12.

Ngginak J., H., J.C. Semangun, Mangimbulude, dan F.S. Rondonuwu. 2013. Komponen Senyawa Aktif pada Udang Serta Aplikasinya dalam Pangan. Sains Medika., 5(2): $128-145$.

Prayitno, D.I, S.I. Nurdiansyah, S.N. Nurbaeti, W. Rahmalia, dan T. Usman. 2018. Ekstraksi dan Analisis Astaxanthin dari Cincalok Dengan Variasi Minyak Nabati. Pertemuan Ilmiah Nasional Tahunan XV ISOI: 165-169.

Rahmayati, R., P.H. Riyadi, L. Rianingsih. 2014. Perbedaan Konsentrasi Garam terhadap Pembentukan Warna Terasi Udang Rebon (Acetes sp.) Basah. J. PHPI., 3: 108-117.

Roopyai, K., T. Parkpoom, S. Prapasri. 2012. Development Of Solid Lipid Nanoparticles Containing Astaxanthin From Shrimp Shell Extract. Department of Pharmaceutics and Industrial Pharmacy, Faculty of Pharmaceutical Sciences, Chulalongkorn University, Bangkok. Thailand. (104-107)

Sachindra, N.M., N. Bhaskar dan N.S. Mahendrakar. 2005. Carotenoid in Different Body Components of Indian Shrimps. J. of Food and Agriculture., 85: 167 - 172.
Silva, A.K., B.D. Rodrigues, L.H. Silva dn A.M. Rodrigues. 2018, Drying and Extraction of Astaxanthin from Pink Shrimp Waste (Farfantepenaeus subtilis): The Applicability of Spouted Beds. J. Food Science and Technology. 1-8. 